\title{
Study of DNA topoisomerase II $\alpha$ expression in canine lymphomas and its potential role as a marker of sensitivity to anthracycline-based chemotherapy in dogs
}

\author{
Pawel Klimiuk $^{1}$, Wojciech Lopuszynski², Kamila Bulak², Anna Smiech ${ }^{2}$, Adam Brzana ${ }^{3}$ \\ ${ }^{1}$ Veterinary Diagnostic Laboratory VetDiagnostyka, Lublin, Poland \\ ${ }^{2}$ Sub-Department of Pathomorphology and Forensic Veterinary Medicine, Department and Clinic \\ of Animal Internal Diseases, University of Life Sciences in Lublin, Poland \\ ${ }^{3}$ Regional Veterinary Inspectorate in Opole, Regional Veterinary Laboratory, Opole, Poland
}

\begin{abstract}
Introduction. Canine lymphoma remains one of the most chemotherapy-responsive neoplasia in dogs. Many factors affect the prognosis in dogs treated for lymphoma, but indications for a specific treatment regimen in individual animals with lymphoma are poorly defined. Topoisomerase II $\alpha$ (TOPII $\alpha$ ) is a key enzyme in DNA replication and a molecular target for TOPII $\alpha$ inhibitors, including anthracyclines. The aim of this study was to determine the expression of TOPII $\alpha$ in canine malignant lymphomas. The relationship between TOPII $\alpha$ expression in canine lymphomas and potential sensitivity of neoplastic cells to anthracycline-based chemotherapy is discussed.

Materials and method. Samples of formalin-fixed paraffin-embedded lymph nodes from 47 dogs with different subtypes of non-Hodgkin's (34 B-cell and 13 T-cell) lymphoma were immunohistochemically labeled with anti-TOPII $\alpha$. The number of positive cells and the intensity of the reaction were taken into account in order to assess TOPII $\alpha$ expression. Results. TOPII $\alpha$ expression was evident in all cases, although differences in the number of positive cells and intensity of the reaction were demonstrated between B-cell and T-cell lymphoma groups as well as within individual groups. Based on the established scoring system, in the B-cell lymphoma group statistically higher expression of TOPII $\alpha$ was found compared to the T-cell lymphoma group $(\mathrm{P}=0.006)$. In $\mathrm{B}$-cell lymphoma group moderate $(41.18 \%)$ and strong $(32.35 \%)$ TOPII $\alpha$ expression predominated, whereas among T-cell lymphoma group the majority were cases with a weak (46.15\%) TOPII $\alpha$ expression.

Conclusion. These preliminary results indicate that further studies are needed to determine the prognostic value of TOPII $\alpha$ expression with regard to the sensitivity of canine B-cell lymphomas to anthracycline-based chemotherapy regimen. Nevertheless, this study indicates the possibility of choosing the appropriate treatment of canine lymphoma based on TOPII $\alpha$ expression. (Folia Histochemica et Cytobiologica 2020, Vol. 58, No. 1, 46-53)
\end{abstract}

Key words: topoisomerase II $\alpha$; dog, lymphoma; immunohistochemistry; chemotherapy

Correspondence address: Wojciech Lopuszynski, DVM PhD Sub-Department of Pathomorphology and Forensic Veterinary Medicine,

Department and Clinic of Animal Internal Diseases,

University of Life Sciences in Lublin, Poland

e-mail: wojciech.lopuszynski@up.lublin.pl

\section{Introduction}

Nearly $90 \%$ of hematological malignancies and about $5-7 \%$ of all neoplasia in dogs are malignant lymphomas, in which chemotherapy is the treatment of choice [1-4]. The main diagnostic test for suspected lymphoma is cytopathological examination of fine needle aspirates collected from enlarged lymph nodes and, according to the WHO guidelines, histopathological examination of the surgically removed lymph node supplemented with 
the immunophenotype assessment [5-8]. Canine lymphomas are very sensitive to chemotherapy, as evidenced by numerous studies which indicate that complete remission (CR) is obtained in about $65 \%$ to $98 \%$ of treated animals [9-16]. In some cases, the remission lasts up to 36 months [9]. Despite the availability of numerous therapy regimens, it is difficult to determine the prognosis, select the optimal treatment method and predict the response to the therapy in each individual patient [12, 17-19]. When selecting a therapy protocol, factors such as lymphoma immunophenotype, histological type and grade of malignancy as well as clinical stage are usually taken into consideration [20-24]. In many cases the response to the treatment regimen is not satisfactory due to the partial remission (PR) or rapid relapse, which implies the need to adjust the treatment protocol with other cytotoxic drugs $[9,10]$. Due to the high cytotoxicity and side effects of drugs used in chemotherapy and the varied response to the treatment protocol, attempts are being made to implement individualized treatment. Targeted therapy aims to adapt the treatment regimen to the type of neoplasia as well as to the individual patient. The therapeutic effect of specific cytotoxic drug differs among individuals despite the same histological type of lymphoma [9, 10, 25-28]. Therefore, prognostic factors that allow the determination of a predictable response to the treatment protocol remain in the area of clinical interest. The potential predictive value of protein markers whose expression changes in the course of neoplastic transformation is of particular interest. One of such markers is DNA topoisomerase II $\alpha$ (TOPII $\alpha$ ) belonging to the family of enzymes involved in DNA replication [29]. The TOPIIa function is associated with condensation and chromosome formation, reorganization of double-stranded DNA and segregation of newly formed chromosomes. TOPII $\alpha$ expression is variable, associated with the phase of the cell cycle. TOPII $\alpha$ expression increases in S phase, reaching peak in $\mathrm{G} 2$ and $\mathrm{M}$ phase, and then decreases at the end of mitosis (G1 phase). TOPII $\alpha$ during the complicated 7-step process leads to the separation of two strands of DNA, allowing cell division [30-33]. The inhibition of the TOPII $\alpha$ function results in permanent links between the DNA strands, and finally in blocking of transcription and replication. Cells with damaged DNA are eliminated by apoptosis [34-37]. TOPII $\alpha$ is therefore a molecular target for antineoplastic drugs such as anthracyclines, which are TOPII $\alpha$ inhibitors [38]. The most commonly used anthracycline drugs to treat lymphomas in dogs are doxorubicin and epirubicin $[9,16,39,40]$. In vivo and in vitro studies carried out on neoplastic cell lines in humans have shown that the sensitivity of neoplastic cells to anthracycline drugs depends on TOPII $\alpha$ cellular expression $[25,30,34,35,41]$. In addition, one study carried out on women with breast cancer treated with mastectomy fol- lowed by adjuvant anthracycline chemotherapy showed that the mortality rate was higher and the free survival time was shorter in patients with TOPII $\alpha$-negative tumors as compared to patients with a positive TOPII $\alpha$ status [31]. A retrospective study on human B-cell lymphomas managed with anthracycline-based chemotherapy revealed that TOPII $\alpha$ expression was significantly associated with the response to chemotherapy, but not to disease-free or overall survival [25]. In veterinary oncology, TOPII $\alpha$ inhibitors are relatively widely used in various chemotherapy protocols with no data on the determination of TOPII $\alpha$ expression levels in canine lymphomas. The aim of the study was to determine the expression of TOPII $\alpha$ in malignant lymphomas in dogs in relation to the potential sensitivity of neoplastic cells to anthracycline-based chemotherapy.

\section{Material and methods}

Animals and design of the study. Dogs of different sex and different age with a suspect of multicentric lymphoma based on clinical symptoms, chest $\mathrm{x}$-rays, abdominal ultrasound, fine needle aspiration biopsy and laboratory tests were considered for inclusion. The studied material consisted of samples of enlarged canine popliteal lymph nodes. Forty-seven samples of lymph nodes were ultimately included upon the histopathological confirmation of lymphoma (stage III and IV according to WHO Clinical Staging System for Lymphosarcoma in Domestic Animals). The animals were not treated with chemotherapy or steroids prior to collection of the lymph nodes. The study design was approved by the local ethics committee.

Histopathological examination. Surgically removed lymph nodes were fixed for 24 hours in $10 \%$ formalin, $\mathrm{pH}=7.2$, and then carried out by alcohol solutions, acetone and xylene to paraffin blocks in a tissue processor (Leica TP-1020). Four $\mu \mathrm{m}$ thick tissue sections were stained with hematoxylin and eosin. The morphological evaluation of stained tissue sections was based on WHO classification criteria [6].

Immunohistochemical evaluation. To determine the lymphoma immunophenotype and to evaluate TOPII $\alpha$ expression, tissue sections were applied to Super Frost slides (Menzel-Glaser) and then incubated at $56^{\circ} \mathrm{C}$ for 12 hours. Tissue sections were dewaxed in xylene and then carried out by decreasing concentrations of alcohols to distilled water. Tissue sections were then immersed in a $0.3 \%$ hydrogen peroxide solution for 15 minutes to block endogenous peroxidase. Incubation with primary antibodies was carried out at $37^{\circ} \mathrm{C}$ in a humidity chamber for 60 minutes. The following primary antibodies were used in the study: polyclonal rabbit anti-CD3 (Dako, Glostrup, Denmark) diluted 1:300; monoclonal mouse anti-CD79 $\alpha$ clone HM57 (Dako, Glostrup, Denmark) diluted 1:100, and mono- 
clonal mouse anti-topoisomerase II $\alpha$ clone Ki-S1 (Dako Glostrup, Denmark) diluted 1:200. Heat-induced antigen retrieval was performed in a specific buffer with proper $\mathrm{pH}$, followed by cooling for $20 \mathrm{~min}$ at room temperature. For immunohistochemical examination, a system for detection of antigen-antibody complexes was used based on secondary antibodies conjugated with biotin directed against primary antibodies (HRP, K0690, Dako, Glostrup, Denmark). The enzyme labeling the reaction site was horseradish peroxidase conjugated with streptavidin and tetrahydrochloride-3'-3-diaminobenzidine (DAB) used as a chromogen (SK-4100, Vector Laboratories, Peterborough, UK). Tissue sections were counterstained with Mayers' hematoxylin and covered with PERTEX (Histolab). In all immunohistochemical reactions, a double-control system was used: a negative control in which the incubation with the primary antibody was replaced with appropriate $\mathrm{IgG}$ sera and a positive control in which the incubation was carried out on palatine tonsil tissue for CD3 and CD79 $\alpha$ and human breast ductal carcinoma for TOPII $\alpha$ with a proven positive reaction with the given antibody. Determination of lymphoma immunophenotype was performed by estimating the expression of CD3 and CD79 $\alpha$ (membrane and cytoplasmic reaction) in tissue sections. The histogenesis of lymphomas was defined as T-cell lymphomas with dominant CD3 expression and B-cell lymphomas with dominant CD79 $\alpha$ expression. A computer-assisted microscopic image analysis system was used to quantify the expression of TOPII $\alpha$. The system included: a light microscope (Nikon Eclipse E-600, Nikon Instruments, Tokyo, Japan) coupled with a digital camera (Nikon DS-Fi1, Nikon Instruments) and a personal computer (PC) with image analysis software (NIS-Elements BR-2.20, Laboratory Imaging, Praha, Czech Republic). The evaluation of TOPII expression was performed by two independent pathologists based on analysis of at least 500 cells in different fields of view at a magnification of $400 \times$. According to the scoring system proposed by Remmele et al. for estrogen receptors, the number of cells with a positive reaction was estimated, where $0=$ no positive cells, $1=\leq 25 \%$ positive cells, $2=$ $26-50 \%$ positive cells, $3=51-75 \%$ positive cells, $4=$ more than $75 \%$ positive cells, and the reaction intensity was evaluated, where $0-$ no reaction, $1-$ mild reaction, $2-$ moderate reaction, 3 - intense reaction [42]. The final result was the product of the parameters (percentage of positive cells $\times$ colored reaction intensity). Based on the obtained number of points and the criteria proposed by Hajduk et al. the expression intensity of TOPII $\alpha$ was determined, where $0-1$ meant no expression $(-), 2-3$ meant weak $(+), 4-8$ moderate $(++)$, and 9-12 strong $(+++)$ expression of TOPII $\alpha$ [31].

Statistical analysis. The obtained results were subjected to statistical analysis. The levels of TOPII $\alpha$ expression between B-cell and T-cell lymphoma groups and between individual subtypes were compared using the Mann-Whitney U test. The minimum
Table 1. Morphological characterization of canine lymphomas in the studied group

\begin{tabular}{|l|c|c|}
\hline Type and subtype of lymphoma & No. of cases & Percentage (\%) \\
\hline B-cell & 34 & 72.34 \\
\hline Diffuse Large B-cell (DLBCL) & 26 & 55.32 \\
\hline Burkitt-type & 5 & 10.63 \\
\hline Marginal zone & 3 & 6.38 \\
\hline T-cell & 13 & 27.66 \\
\hline T-cell not otherwise specified & 9 & 19.15 \\
\hline Nodal T-zone & 2 & 4.26 \\
\hline Lymphoblastic & 2 & 4.26 \\
\hline Total & 47 & 100.00 \\
\hline
\end{tabular}

level of significance was set at $\mathrm{P}<0.05$. Statistical analysis was carried out using STATISTICA v 9.1 (StatSoft, Poland).

\section{Results}

The age of dogs ranged from 4 to 14 years (average age 7 years). There were 23 female dogs (49\%) and 24 male dogs $(51 \%)$. The studied population consisted of purebred dogs with 38 individuals (80.85\%), and among them the most numerous were German Shepherds (17\%) and boxers (14.9\%). Mixed-breed dogs constituted $19.15 \%$ of the studied population.

On the basis of immunohistochemical examination 34 (72.34\%) B-cell lymphomas and 13 (27.66\%) T-cell lymphomas were diagnosed (Table 1). The following subtypes of lymphoma were recognized: diffuse large B-cell lymphoma (DLBCL) in 26 of all cases $(55.32 \%)$, Burkitt-type lymphoma - in 5 of all cases $(10.63 \%)$, marginal zone B-cell lymphoma - in 3 of all cases $(6.38 \%)$, peripheral T-cell lymphoma not otherwise specified (PTCL) - in 9 of all cases (19.15\%), nodal T-zone lymphoma (TZL) - in 2 of all cases $(4.26 \%)$, and lymphoblastic lymphoma (T-LBL) - in 2 of all cases $(4.26 \%)$.

TOPII $\alpha$ expression was evident in all cases with a diffuse granular nuclear pattern, although the variability in the reaction intensity and the number of positive cells were demonstrated (Fig. 1). Higher expression of TOPII $\alpha$ was observed at the periphery of the examined lymph nodes, and a weaker reaction was obtained in the central areas of the lymph nodes. Based on the established TOPII $\alpha$ expression scoring system, in the B-cell lymphoma group the most numerous were cases with moderate TOPII $\alpha$ expression (14 cases, $41.18 \%$ ), whereas in the T-cell lymphoma group, weak expression predominated (6 cases, $46.15 \%$ ). B-cell lymphomas with strong TOPII $\alpha$ expression included 11 cases 

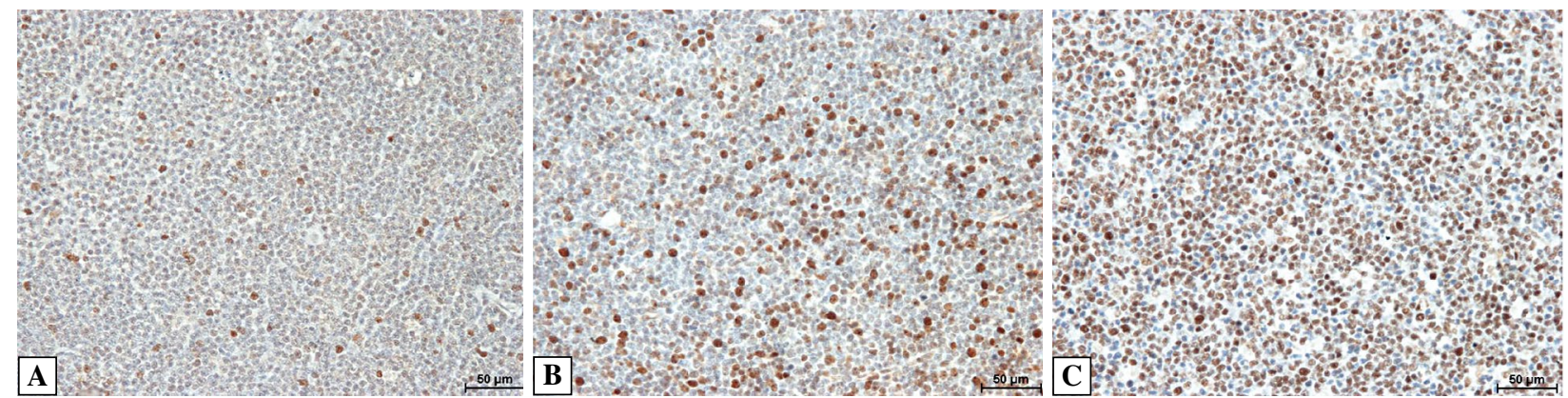

Figure 1. Diversity of TOPII $\alpha$ expression in canine lymph nodes with diffuse large B-cell lymphoma. (A) weak expression (score 2-3), (B) moderate expression (score 4-8), (C) strong expression (score 9-12). Immunohistochemistry, anti-TOPII $\alpha$, clone Ki-S1, Mayer's hematoxylin counterstain. Bar $=50 \mu \mathrm{m}$.

Table 2. TOPII $\alpha$ expression in the studied groups of canine lymphomas

\begin{tabular}{|l|c|c|}
\hline TOPII $\alpha$ expression & $\begin{array}{c}\text { B-cell lymphoma } \\
\text { (No. of cases = 34) }\end{array}$ & $\begin{array}{c}\text { T-cell lymphoma } \\
\text { (No. of cases = 13) }\end{array}$ \\
\hline$(-)$ & 0 & 2 \\
& $0.00 \%$ & $15.38 \%$ \\
\hline Weak $(+)$ & 9 & 6 \\
& $26.47 \%$ & $46.15 \%$ \\
\hline Moderate (++) & 14 & 5 \\
& $41.18 \%$ & $38.46 \%$ \\
\hline Strong $(+++)$ & 11 & 0 \\
& $32.35 \%$ & $0.00 \%$ \\
\hline & \multicolumn{2}{|c|}{$\mathrm{U}=107.0 \quad \mathrm{P}=0.006$} \\
\hline
\end{tabular}

(32.35\%), while weak expression was found in 9 cases $(26.47 \%)$. In the T-cell lymphoma group no cases with strong TOPII $\alpha$ expression were found. Concurrently, in the B-cell lymphoma group no cases with lacking TOPII $\alpha$ expression were recorded (Table 2). In the B-cell lymphoma group statistically higher expression of TOPII $\alpha$ was found compared to the
T-cell lymphoma group $(\mathrm{P}=0.006)$. In all analyzed lymphoma subtypes there were differences in TOPII $\alpha$ expression. The moderate and strong TOPII $\alpha$ expression predominated in the most numerous subtype of DLBCL (Table 3). In the case of Burkitt-type lymphoma, strong or moderate expression was found in all cases, in the absence of weak-expression cases. In the PTCL group; however, cases with weak and moderate TOPII $\alpha$ expression predominated, as in the case of TZL and T-LBL. Unfortunately, too few cases in particular subtypes made statistical analysis between lymphoma subtypes impossible.

\section{Discussion}

In this study conducted on a group of 47 dogs with non-Hodgkin's lymphomas, the majority were B-cell lymphomas, whereas T-cell lymphomas were less frequent, as confirmed by other literature data $[6$, $7,16,27,43]$. In the vast majority of cases (45 dogs), positive immunohistochemical reaction with varied intensity was observed. Only in 2 cases in the studied group the TOPII $\alpha$ expression was lacking. Statistically

Table 3. Results of immunochistochemical assessment of TOPII $\alpha$ in studied subtypes of B-cell and T-cell canine lymphomas

\begin{tabular}{|c|c|c|c|c|c|c|}
\hline \multirow[t]{2}{*}{ TOPII $\alpha$ expression } & \multicolumn{3}{|c|}{ B-cell lymphoma } & \multicolumn{3}{|c|}{ T-cell lymphoma } \\
\hline & DLBCL $^{a}$ & Burkitt-type & $\mathbf{M Z L}^{\mathrm{b}}$ & PTCL $^{\mathrm{c}}$ & $\mathbf{T Z L}^{\mathrm{d}}$ & T-LBL ${ }^{\mathrm{e}}$ \\
\hline No. of cases & 26 & 5 & 3 & 9 & 2 & 2 \\
\hline No expression (-) & $\begin{array}{c}0 \\
0.00 \%\end{array}$ & $\begin{array}{c}0 \\
0.00 \%\end{array}$ & $\begin{array}{c}0 \\
0.00 \%\end{array}$ & $\begin{array}{c}1 \\
11.11 \%\end{array}$ & $\begin{array}{c}1 \\
50.00 \%\end{array}$ & $\begin{array}{c}0 \\
0.00 \%\end{array}$ \\
\hline Weak $(+)$ & $\begin{array}{c}7 \\
26.92 \%\end{array}$ & $\begin{array}{c}0 \\
0.00 \%\end{array}$ & $\begin{array}{c}2 \\
66.67 \%\end{array}$ & $\begin{array}{c}4 \\
44.44 \%\end{array}$ & $\begin{array}{c}1 \\
50.00 \%\end{array}$ & $\begin{array}{c}1 \\
50.00 \%\end{array}$ \\
\hline Moderate $(++)$ & $\begin{array}{c}11 \\
42.31 \%\end{array}$ & $\begin{array}{c}2 \\
40.00 \%\end{array}$ & $\begin{array}{c}1 \\
33.33 \%\end{array}$ & $\begin{array}{c}4 \\
44.44 \%\end{array}$ & $\begin{array}{c}0 \\
0.00 \%\end{array}$ & $\begin{array}{c}1 \\
50.00 \%\end{array}$ \\
\hline Strong $(+++)$ & $\begin{array}{c}8 \\
30.77 \%\end{array}$ & $\begin{array}{c}3 \\
60.00 \%\end{array}$ & $\begin{array}{c}0 \\
0.00 \%\end{array}$ & $\begin{array}{c}0 \\
0.00 \%\end{array}$ & $\begin{array}{c}0 \\
0.00 \%\end{array}$ & $\begin{array}{c}0 \\
0.00 \%\end{array}$ \\
\hline
\end{tabular}

${ }^{a}$ DLBCL — diffuse large B-cell lymphoma; ${ }^{b} \mathrm{MZL}$ — marginal zone B-cell lymphoma; ${ }^{\mathrm{c} T C L}$ — peripheral T-cell lymphoma not otherwise specified; ${ }^{\mathrm{d}} \mathrm{TZL}$ — nodal T-zone lymphoma; ${ }^{\mathrm{e}} \mathrm{T}-\mathrm{LBL}$ — T-cell lymphoblastic lymphoma 
higher TOPII $\alpha$ expression was demonstrated in the B-cell lymphoma group $(\mathrm{P}=0.006)$ in which moderate $(41.18 \%)$ and strong $(32.35 \%)$ TOPII $\alpha$ expression predominated, whereas among T-cell lymphomas the majority were lymphomas with a weak $(46.15 \%)$ TOPII $\alpha$ expression. The obtained results may indicate a potentially greater chemosensitivity of canine B-cell lymphomas to the action of TOPII $\alpha$ inhibitors. Based on the literature data the use of TOPII $\alpha$ inhibitors in dogs with B-cell lymphomas results in a better therapeutic effect and a longer-lasting remission compared to dogs with T-cell lymphomas. In the study of Beaver et al. the use of a single dose of doxorubicin in dogs with B-cell lymphoma resulted in a CR in $86 \%$ of dogs and a PR in $13.8 \%$ of dogs, whereas in dogs with $\mathrm{T}$-cell lymphoma remission was obtained only in 50\% of treated animals [27]. Similar dependencies have been demonstrated in other studies in which single or multi-drug protocols containing TOPII $\alpha$ inhibitors were used [10, 11, 16, 23, 44-48]. In addition, differences in the response to different treatment protocols were observed in individual dogs with the B-cell or T-cell lymphoma. In one study, dogs with B-cell lymphoma treated with doxorubicin in combination with L-asparaginase and prednisone $71 \%$ of animals achieved CR while in $13 \%$ PR occurred. Remission time ranged from a few days to 414 days, and the total survival time ranged from several days to 566 days [9]. Study in dogs with T-cell lymphoma showed that $88 \%$ of dogs treated with the chemotherapy protocol consisted of cyclophosphamide, doxorubicin hydrochloride (hydroxydaunorubicin), vincristine sulfate (Oncovin), and prednisone (CHOP protocol) achieved CR, $8 \%$ of dogs had PR, and 4\% of dogs had no response. Remission time ranged from 84 to 126 days, and the overall survival time varied from 167 to 244 days [11]. Similar differences in response to treatment using different protocols containing TOPII $\alpha$ inhibitors in relation to various subtypes of B-cell and T-cell lymphomas have been demonstrated in other studies [12, 21, 26, 27, 49]. Our study revealed that both B-cell and T-cell lymphoma group showed differentiated TOPII $\alpha$ expression. Noteworthy is also the fact that a weak expression of TOPII $\alpha$ was found in $26.47 \%$ of B-cell lymphomas in our study. This study showed that cases of low TOPII $\alpha$ expression and lack of TOPII $\alpha$ expression were observed in specific lymphoma subtypes. In the case of DLBCL diagnosed in 26 dogs, the percentage of weak-expression cases was $26.92 \%$, and in the case of PTCL diagnosed in 9 dogs, nearly half $(44.44 \%)$ had weak expression. This may explain why some dogs with B-cell lymphoma do not respond or partially respond to TOPII $\alpha$ inhibitors. It is worth mentioning that cy- totoxic drugs can cause numerous side effects and in extreme cases can lead to the patient's death [16, 40, $44,51]$. Unfortunately, despite the use of numerous lymphoma classifications, it is currently not possible, based solely on histopathological examination and the lymphoma immunophenotype, to determine the most effective therapy for individual patient. Based on the histological malignancy grade and taking into account the clinical stage of the disease, the biological behavior of the lymphoma can be predicted with high probability, and thus the choice of therapeutic treatment can be made, while in some cases, the therapy may be discontinued. However, the updated Kiel classification for lymphomas does not answer the question whether the use of a specific cytotoxic drug within a selected scheme used for a specific type of lymphoma with respect to a particular patient will bring satisfactory results $[22,23,50]$. In many cases, the use of the same chemotherapy protocol in two different patients with the same histological type of lymphoma gave different treatment effects, with different periods of remission and survival time [9, $10,19,26,27]$. The diversity of TOPII $\alpha$ expression in this study, despite the predominance of moderate to strong TOPII $\alpha$ expression in B-cell lymphoma, does not show that the lymphoma immunophenotype and histological type are closely related to the level of TOPII $\alpha$ expression.

There is currently growing interest in the potential prognostic value of markers that are the molecular target for cytotoxic drugs. One such marker is DNA topoisomerase II $\alpha$, whose inhibitors are cytotoxic drugs from the anthracycline group, including commonly used doxorubicin [30,32]. Doxorubicin is one of the drugs included in the CHOP protocol considered the most effective treatment protocol in non-Hodgkin's lymphoma in dogs [18, 19, 27]. The second most commonly used scheme in the treatment of lymphoma is the COP protocol including prednisolone, cyclophosphamide and vincristine. It is assumed that the addition of doxorubicin to the treatment protocol increases its effectiveness, but this effect is observed only in individual dogs $[19,52]$. An explanation for the observed differences in the effects of implemented treatment in clinical trials seems to be the diverse TOPII $\alpha$ expression found in our study, both between B-cell and T-cell lymphoma group and their subtypes. In addition, the adverse reactions associated with the use of doxorubicin are observed. The most common is the cardiotoxicity that develops with long-term use and chemotherapy-induced myelotoxicity $[14,40,51$, 53]. The possibility of determining in which patients the use of doxorubicin would be beneficial and in which its use would not bring satisfactory results 
seems to be crucial in choosing the optimal treatment protocol and minimizing the possibility of side effects.

Immunohistochemical studies on the predictive and prognostic value of TOPII $\alpha$ expression have been conducted in human medicine [33, 36, 41]. Special interest among researchers was aroused by the expression of TOPII $\alpha$ in breast cancer in women. The reason for this interest is the fact that one of the main drugs used in the treatment of breast cancer are anthracycline [30, 31]. A variable response was observed for its use in the treatment of women with the same histological type of breast cancer [31]. Immunohistochemical studies have shown different TOPII $\alpha$ expression in various histological types of breast tumors and in the same histological types of breast cancer of different women [35]. Similar observations were also made in patients with various types of soft tissue sarcomas, testicular, ovarian, lung and gastric cancer [54-60]. Despite the widespread use of doxorubicin in the treatment of various types of neoplasia (including lymphomas) in animals, no preliminary studies have yet been conducted in veterinary medicine to assess the sensitivity of particular types of neoplasia to anthracyclins. There are also no literature reports describing TOPII $\alpha$ expression in various types of neoplasia in dogs. In vitro and in vivo studies performed on human neoplastic cell lines showed that cells with higher TOPII $\alpha$ expression exhibit greater sensitivity to anthracyclines, whereas cells with lower expression of TOPII $\alpha$ have a significantly lower sensitivity $[25,34]$. In clinical trials, human patients with breast cancer overexpressing TOPII $\alpha$ showed a better response to treatment with anthracyclines than those with low TOPII $\alpha$ expression $[30,31,35]$. In addition, in human medicine for the evaluation of the TOPII $\alpha$ expression itself, attempts were made to determine the TOPII $\alpha$ gene amplification and its correlation with the TOPII $\alpha$ expression at the cellular level. Nevertheless, there is no unambiguous consensus between TOPII $\alpha$ gene amplification and TOPII $\alpha$ expression, which may indicate the existence of other mechanism than amplification that affect TOPII $\alpha$ overexpression [30]. This may suggest that assessing TOPII $\alpha$ expression in tissues is more useful than determining TOPII $\alpha$ gene amplification.

In the conducted study, a human monoclonal antibody was used to assess TOPII $\alpha$ expression and this antibody demonstrated cross-reactivity with a dog tissue. The author's original scoring system was used to assess the expression of TOPII $\alpha$, in which both the number of positive cells and the intensity of the reaction were taken into account. Doubts of many authors arouse the lack of a uniform pattern that allows objectively evaluate and interpret the expression of TOPII $\alpha$. The problem is to determine the so-called cut-off point where the expression of TOPII $\alpha$ can be assessed as weak, moderate or strong. Most authors in human medicine determine the observed correlations between the expression of TOPII $\alpha$ and the response to treatment with anthracyclines, without a measurable determination of the level of this expression. Hajduk et al. investigating the expression of TOPII $\alpha$ in breast cancer cells assumed that the lack of expression is when the number of positive cells does not exceed $5 \%$, weak $6-30 \%$, moderate $31-60 \%$, while strong expression is more than $60 \%$ of positive cells [31]. Pentheroudakis et al. in studies on TOPII $\alpha$ expression in diffuse large B-cell lymphomas (DLBCL) in human patients, assessed that strong-expressive TOPII $\alpha$ lymphomas are those in which positive cells account for more than $80 \%$ of all cells, the others (less than $80 \%$ ) are lymphomas with weak expression of TOPII $\alpha$. In the study group, lymphomas with strong TOPII $\alpha$ expression accounted for as much as $91 \%$ of all DLBCL [25]. In the study of Hajduk et al. a positive correlation was observed between the increase in TOPII $\alpha$ expression and the increase in response to anthracycline treatment [31]. It is considered unreasonable to use anthracycline-based chemotherapy with weak TOPII $\alpha$ expression. This means that the use of doxorubicin in dogs with weak TOPII $\alpha$ expression may not bring noticeable therapeutic effects or may lead to a significant reduction in the effectiveness of therapy with other cytotoxic drugs leading to the increased risk of multidrug resistance in cells [1].

This study corresponds to the trend of research on prognostic factors in the chemotherapy of dogs with lymphoma [17, 61]. This is the first paper describing the importance and potential role of determining the TOPII $\alpha$ expression in veterinary oncology. The study has been conducted in a small number of cases; however, given the mechanism of anti-tumor effects of TOPII $\alpha$ inhibitors, it shows that immunohistochemical determination of TOPII $\alpha$ expression might be helpful in the selection of the optimal treatment regimen for non-Hodgkin's lymphomas in dogs. However, further studies are needed to assess the relationship between TOPII $\alpha$ expression and other prognostic factors, including the histological type, proliferation rate, grade and clinical stage of the disease. Clinical trials are also necessary to assess the correlation between TOPII $\alpha$ expression and long-term clinical outcomes including the survival time and remission rates in animal patients treated with different chemotherapy protocols containing TOPII $\alpha$ inhibitors.

\section{References}

1. Zandvliet M. Canine lymphoma: a review. Veterinary Quarterly. 2016; 36(2): 76-104, doi: 10.1080/01652176.2016.1152633. 
2. Vail D, Pinkerton M, Young K. Hematopoietic tumours. In: Withrow SJ, Vail DM, Page RL, eds. Withrow \& MacEwen's Small Animal Clinical Oncology. 5th ed. St Louis, MO: Elsevier; 2013: 608.

3. Br nden LB, Nielsen SS, Toft N, et al. Data from the Danish veterinary cancer registry on the occurrence and distribution of neoplasms in dogs in Denmark. Vet Rec. 2010; 166(19): 586-590, doi: 10.1136/vr.b4808, indexed in Pubmed: 20453236.

4. Merlo DF, Rossi L, Pellegrino C, et al. Cancer incidence in pet dogs: findings of the Animal Tumor Registry of Genoa, Italy. J Vet Intern Med. 2008; 22(4): 976-984, doi: 10.1111/j.19391676.2008.0133.x, indexed in Pubmed: 18564221.

5. Sapierzyński R, Kliczkowska-Klarowicz K, Jankowska U, et al. Cytodiagnostics of canine lymphomas - possibilities and limitations. Pol J Vet Sci. 2016; 19(2): 433-439, doi: 10.1515/ pjvs-2016-0055, indexed in Pubmed: 27487521.

6. Valli VE, San Myint M, Barthel A, et al. Classification of canine malignant lymphomas according to the World Health Organization criteria. Vet Pathol. 2011; 48(1): 198-211, doi: 10.1177/0300985810379428, indexed in Pubmed: 20861499.

7. Ponce F, Marchal T, Magnol JP, et al. A morphological study of 608 cases of canine malignant lymphoma in France with a focus on comparative similarities between canine and human lymphoma morphology. Vet Pathol. 2010; 47(3): 414-433, doi: 10.1177/0300985810363902, indexed in Pubmed: 20472804.

8. Teske E, van Heerde P. Diagnostic value and reproducibility of fine-needle aspiration cytology in canine malignant lymphoma. Vet Q. 1996; 18(3): 112-115, doi: 10.1080/01652176.1996.9694630, indexed in Pubmed: 8903146.

9. Al-Nadaf S, Rebhun RB, Curran KM, et al. Retrospective analysis of doxorubicin and prednisone as first-line therapy for canine B-cell lymphoma. BMC Vet Res. 2018; 14(1): 356, doi: 10.1186/s12917-018-1688-5, indexed in Pubmed: 30458771.

10. Curran K, Thamm DH. Retrospective analysis for treatment of naïve canine multicentric lymphoma with a 15 -week, maintenance-free CHOP protocol. Vet Comp Oncol. 2016; 14 Suppl 1: 147-155, doi: 10.1111/vco.12163, indexed in Pubmed: 26279153.

11. Rebhun RB, Kent MS, Borrofka SA, et al. CHOP chemotherapy for the treatment of canine multicentric T-cell lymphoma. Vet Comp Oncol. 2011; 9(1): 38-44, doi: 10.1111/j.14765829.2010.00230.x, indexed in Pubmed: 21303452.

12. Flory AB, Rassnick KM, Erb HN, et al. Evaluation of factors associated with second remission in dogs with lymphoma undergoing retreatment with a cyclophosphamide, doxorubicin, vincristine, and prednisone chemotherapy protocol: 95 cases (2000-2007). J Am Vet Med Assoc. 2011; 238(4): 501-506, doi: 10.2460/javma.238.4.501, indexed in Pubmed: 21320021.

13. Brodsky EM, Maudlin GN, Lachowicz JL, et al. Asparaginase and MOPP treatment of dogs with lymphoma. J Vet Intern Med. 2009; 23(3): 578-584, doi: 10.1111/j.19391676.2009.0289.x, indexed in Pubmed: 19645842.

14. Daters AT, Mauldin GE, Mauldin GN, et al. Evaluation of a multidrug chemotherapy protocol with mitoxantrone based maintenance (CHOP-MA) for the treatment of canine lymphoma. Vet Comp Oncol. 2010; 8(1): 11-22, doi: 10.1111/j.1476-5829.2009.00199.x, indexed in Pubmed: 20230577.

15. Rassnick KM, Bailey DB, Malone EK, et al. Comparison between L-CHOP and an L-CHOP protocol with interposed treatments of CCNU and MOPP (L-CHOP-CCNU-MOPP) for lymphoma in dogs. Vet Comp Oncol. 2010; 8(4): 243-253, doi: 10.1111/j.1476-5829.2010.00224.x, indexed in Pubmed: 21062406.

16. Simon D, Nolte I, Eberle N, et al. Treatment of dogs with lymphoma using a 12 -week, maintenance-free combination chemotherapy protocol. J Vet Intern Med. 2006; 20(4): 948-954, doi: 10.1892/0891-6640(2006)20[948:todwlu]2.0.co;2, indexed in Pubmed: 16955821.
17. Legendre AM. Treatment of dogs with lymphoma: a work in progress. J Vet Intern Med. 2007; 21(6): 1166-1167, doi: 10.1892/0891-6640(2007)21[1166:todwla]2.0.co;2, indexed in Pubmed: 18196720.

18. Baskin CR, Couto CG, Wittum TE. Factors influencing first remission and survival in 145 dogs with lymphoma: a retrospective study. J Am Anim Hosp Assoc. 2000; 36(5): 404-409, doi: 10.5326/15473317-36-5-404, indexed in Pubmed: 10997515 .

19. Chun R. Lymphoma: which chemotherapy protocol and why? Top Companion Anim Med. 2009; 24(3): 157-162, doi: 10.1053/j.tcam.2009.03.003, indexed in Pubmed: 19732735.

20. Moore A. Treatment of T cell lymphoma in dogs. Veterinary Record. 2016; 179(11): 277-277, doi: 10.1136/vr.103456.

21. Valli VE, Kass PH, San Myint M, et al. Canine lymphomas: association of classification type, disease stage, tumor subtype, mitotic rate, and treatment with survival. Vet Pathol. 2013; 50(5): 738-748, doi: 10.1177/0300985813478210, indexed in Pubmed: 23444036.

22. Bienzle D, Vernau W. The diagnostic assessment of canine lymphoma: implications for treatment. Clin Lab Med. 2011; 31(1): 21-39, doi: 10.1016/j.cll.2010.10.001, indexed in Pubmed: 21295720.

23. Ponce F, Magnol JP, Ledieu D, et al. Prognostic significance of morphological subtypes in canine malignant lymphomas during chemotherapy. Vet J. 2004; 167(2): 158-166, doi: 10.1016/j.tvjl.2003.10.009, indexed in Pubmed: 14975390.

24. Carter RF, Harris CK, Withrow SJ, et al. Chemotherapy of canine lymphoma with histopathological correlation: Doxorubicin alone compared to $\mathrm{COP}$ as first treatment regimen. J Am Anim Hosp Assoc. 1987; 23: 587-596.

25. Pentheroudakis G, Goussia A, Voulgaris E, et al. High levels of topoisomerase IIalpha protein expression in diffuse large B-cell lymphoma are associated with high proliferation, germinal center immunophenotype, and response to treatment. Leuk Lymphoma. 2010; 51(7): 1260-1268, doi: 10.3109/10428194.2010.483749, indexed in Pubmed: 20497003

26. Childress MO, Ramos-Vara JA, Ruple A. Retrospective analysis of factors affecting clinical outcome following CHOPbased chemotherapy in dogs with primary nodal diffuse large B-cell lymphoma. Vet Comp Oncol. 2018; 16(1): E159-E168, doi: 10.1111/vco.12364, indexed in Pubmed: 29152834.

27. Beaver LM, Strottner G, Klein MK. Response rate after administration of a single dose of doxorubicin in dogs with B-cell or T-cell lymphoma: 41 cases (2006-2008). J Am Vet Med Assoc. 2010; 237(9): 1052-1055, doi: 10.2460/javma.237.9.1052, indexed in Pubmed: 21034344.

28. Chun R, Garrett LD, Vail DM. Evaluation of a high-dose chemotherapy protocol with no maintenance therapy for dogs with lymphoma. J Vet Intern Med. 2000; 14(2): 120-124, doi: 10.1892/0891-6640(2000)014<0120:eoahcp>2.3.co;2, indexed in Pubmed: 10772481.

29. Nitiss J. Targeting DNA topoisomerase II in cancer chemotherapy. Nature Reviews Cancer. 2009; 9(5): 338-350, doi: 10.1038/nrc2607.

30. Sosinska-Mielcarek K, Jassem J. Predictive role of topoisomerase II expression in anthracycline based breast cancer chemotherapy. Nowotwory. Journal of Oncology. 2005; 55(3): 252-256.

31. Hajduk M, Olszewski WP, Smietana A. Evaluation of the predictive value of topoisomerase II alpha in patients with breast carcinoma. Pol J Pathol. 2009; 60(3): 115-123, indexed in Pubmed: 20069504.

32. Nitiss J. Targeting DNA topoisomerase II in cancer chemotherapy. Nature Reviews Cancer. 2009; 9(5): 338-350, doi: $10.1038 / \mathrm{nrc} 2607$.

33. Zijlstra JG, de Jong S, de Vries EG, et al. Topoisomerases, new targets in cancer chemotherapy. Med Oncol Tumor 
Pharmacother. 1990; 7(1): 11-18, doi: 10.1007/bf03000485, indexed in Pubmed: 2160032.

34. Burgess DJ, Doles J, Zender L, et al. Topoisomerase levels determine chemotherapy response in vitro and in vivo. Proc Natl Acad Sci U S A. 2008; 105(26): 9053-9058, doi: 10.1073/ pnas.0803513105, indexed in Pubmed: 18574145.

35. Villman K, Sjöström J, Heikkilä R, et al. TOP2A and HER2 gene amplification as predictors of response to anthracycline treatment in breast cancer. Acta Oncol. 2006; 45(5): 590-596, doi: 10.1080/02841860500543182, indexed in $\mathrm{Pu}-$ bmed: 16864174.

36. Smith PJ, Sou s S. Multilevel therapeutic targeting by topoisomerase inhibitors. Br J Cancer Suppl. 1994; 23: S47-S51, indexed in Pubmed: 8075006.

37. Bodley A, Liu LF, Israel M, et al. DNA topoisomerase II-mediated interaction of doxorubicin and daunorubicin congeners with DNA. Cancer Res. 1989; 49(21): 5969-5978, indexed in Pubmed: 2551497.

38. Mordente A, Meucci E, Martorana GE, et al. Topoisomerases and Anthracyclines: Recent Advances and Perspectives in Anticancer Therapy and Prevention of Cardiotoxicity. Curr Med Chem. 2017; 24(15): 1607-1626, doi: 10.2174/09298673 23666161214120355 , indexed in Pubmed: 27978799.

39. Wang SL, Lee JJ, Liao AT. Comparison of efficacy and toxicity of doxorubicin and mitoxantrone in combination chemotherapy for canine lymphoma. Can Vet J. 2016; 57(3): 271-276, indexed in Pubmed: 26933263.

40. Valerius KD, Ogilvie GK, Mallinckrodt CH, et al. Doxorubicin alone or in combination with asparaginase, followed by cyclophosphamide, vincristine, and prednisone for treatment of multicentric lymphoma in dogs: 121 cases (1987-1995). J Am Vet Med Assoc. 1997; 210(4): 512-516, indexed in Pubmed: 9040837.

41. Dwarakanath BS, Khaitan D, Mathur R. Inhibitors of topoisomerases as anticancer drugs: problems and prospects. Indian J Exp Biol. 2004; 42(7): 649-659, indexed in Pubmed: 15339028.

42. Remmele W, Stegner HE. [Recommendation for uniform definition of an immunoreactive score (IRS) for immunohistochemical estrogen receptor detection (ER-ICA) in breast cancer tissue]. Pathologe. 1987; 8(3): 138-140, indexed in Pubmed: 3303008.

43. Valli VE, Vernau W, de Lorimier LP, et al. Canine indolent nodular lymphoma. Vet Pathol. 2006; 43(3): 241-256, doi: 10.1354/vp.43-3-241, indexed in Pubmed: 16672571.

44. Morgan E, O'Connell K, Thomson M, et al. Canine T cell lymphoma treated with lomustine, vincristine, procarbazine, and prednisolone chemotherapy in 35 dogs. Vet Comp Oncol. 2018; 16(4): 622-629, doi: 10.1111/vco.12430, indexed in Pubmed: 30117253.

45. Sorenmo K, Overley B, Krick E, et al. Outcome and toxicity associated with a dose-intensified, maintenance-free CHOPbased chemotherapy protocol in canine lymphoma: 130 cases. Vet Comp Oncol. 2010; 8(3): 196-208, doi: 10.1111/j.14765829.2010.00222.x, indexed in Pubmed: 20691027.

46. Rassnick KM, Bailey DB, Malone EK, et al. Comparison between L-CHOP and an L-CHOP protocol with interposed treatments of CCNU and MOPP (L-CHOP-CCNU-MOPP) for lymphoma in dogs. Vet Comp Oncol. 2010; 8(4): 243-253, doi: 10.1111/j.1476-5829.2010.00224.x, indexed in Pubmed: 21062406.

47. Rebhun RB, Lana SE, Ehrhart EJ, et al. Comparative analysis of survivin expression in untreated and relapsed canine lymphoma. J Vet Intern Med. 2008; 22(4): 989-995, doi: 10.1111/j.1939-1676.2008.0143.x, indexed in Pubmed: 18647159 .
48. Edwards DS, Henley WE, Harding EF, et al. Breed incidence of lymphoma in a UK population of insured dogs. Vet Comp Oncol. 2003; 1(4): 200-206, doi: 10.1111/j.14765810.2003.00025.x, indexed in Pubmed: 19379181.

49. Sierra Matiz OR, Santilli J, Anai LA, et al. Prognostic significance of Ki67 and its correlation with mitotic index in dogs with diffuse large B-cell lymphoma treated with 19-week CHOP-based protocol. J Vet Diagn Invest. 2018; 30(2): 263-267, doi: 10.1177/1040638717743280, indexed in Pubmed: 29192554.

50. Sayag D, Fournel-Fleury C, Ponce F. Prognostic significance of morphotypes in canine lymphomas: A systematic review of literature. Vet Comp Oncol. 2018; 16(1): 12-19, doi: 10.1111/ vco.12320, indexed in Pubmed: 28524622.

51. Hallman BE, Hauck ML, Williams LE, et al. Incidence and risk factors associated with development of clinical cardiotoxicity in dogs receiving doxorubicin. J Vet Intern Med. 2019; 33(2): 783-791, doi: 10.1111/jvim.15414, indexed in Pubmed: 30697816.

52. Keller ET, MacEwen EG, Rosenthal RC, et al. Evaluation of prognostic factors and sequential combination chemotherapy with doxorubicin for canine lymphoma. J Vet Intern Med. 1993; 7(5): 289-295, doi: 10.1111/j.1939-1676.1993.tb01021.x, indexed in Pubmed: 8263847.

53. Volkova M, Russell R. Anthracycline cardiotoxicity: prevalence, pathogenesis and treatment. Curr Cardiol Rev. 2011; 7(4): 214-220, doi: 10.2174/157340311799960645, indexed in Pubmed: 22758622.

54. Miura Y, Kaira K, Sakurai R, et al. High expression of topoisomerase-II predicts favorable clinical outcomes in patients with relapsed small cell lung cancers receiving amrubicin. Lung Cancer. 2018; 115: 42-48, doi: 10.1016/j.lungcan.2017.11.010, indexed in Pubmed: 29290260.

55. González-Molleda L, Wang Y, Yuan Y. Potent antiviral activity of topoisomerase I and II inhibitors against Kaposi's sarcoma-associated herpesvirus. Antimicrob Agents Chemother. 2012; 56(2): 893-902, doi: 10.1128/AAC.05274-11, indexed in Pubmed: 22106228.

56. Faggad A, Darb-Esfahani S, Wirtz R, et al. Topoisomerase IIalpha mRNA and protein expression in ovarian carcinoma: correlation with clinicopathological factors and prognosis. Mod Pathol. 2009; 22(4): 579-588, doi: 10.1038/modpathol.2009.14, indexed in Pubmed: 19270648.

57. Dimov ND, Zynger DL, Luan C, et al. Topoisomerase II alpha expression in testicular germ cell tumors. Urology. 2007; 69(5): 955-961, doi: 10.1016/j.urology.2007.01.068, indexed in Pubmed: 17482942.

58. Chekerov R, Klaman I, Zafrakas M, et al. Altered expression pattern of topoisomerase IIalpha in ovarian tumor epithelial and stromal cells after platinum-based chemotherapy. Neoplasia. 2006; 8(1): 38-45, doi: 10.1593/neo.05580, indexed in Pubmed: 16533424.

59. Withoff S, van der Zee AG, de Jong S, et al. DNA topoisomerase IIalpha and -beta expression in human ovarian cancer. $\mathrm{Br}$ J Cancer. 1999; 79(5-6): 748-753, doi: 10.1038/sj.bjc.6690120, indexed in Pubmed: 10070864.

60. Giaccone G, van Ark-Otte J, Scagliotti G, et al. Differential expression of DNA topoisomerases in non-small cell lung cancer and normal lung. Biochim Biophys Acta. 1995; 1264(3): 337-346, doi: 10.1016/0167-4781(95)00171-9, indexed in Pubmed: 8547322 .

61. Argyle DJ, Pecceu E. Canine and feline lymphoma: challenges and opportunities for creating a paradigm shift. Vet Comp Oncol. 2016; 14 Suppl 1: 1-7, doi: 10.1111/vco.12253, indexed in Pubmed: 27505685.

Submitted: 28 November, 2019

Accepted after reviews: 26 February, 2020 Available as AoP: 16 March, 2020 